\title{
AMEC Project 1.4-1 \\ SOLID RADIOACTIVE WASTE STORAGE TECHNOLOGIES: PERFORMANCE OF A POLYMER SEALANT COATING IN AN ARCTIC MARINE ENVIRONMENT
}

\author{
Technical Experts/Authors \\ Melvyn G. Cowgill and Paul D. Moskowitz, Brookhaven National Laboratory \\ Lev M. Chernaenko, Interbranch Coordination Scientific-Technical Center \\ Of Nuclide Production \\ Ashot Nazarian, Science Applications International Corporation
}

\section{Project Officers}

Andrew Griffith, U.S. Department of Energy Alexander Diashev, Russian Ministry of Defence

Thor Engøy, Norwegian Deience Research Establishment

Spring 2000

\author{
Arctic Military Environmental Cooperation \\ US Department of Defense \\ Washington, DC, USA
}





\title{
AMEC Project 1.4-1 \\ SOLID RADIOACTIVE WASTE STORAGE TECHNOLOGIES: PERFORMANCE OF A POLYMER SEALANT COATING IN AN ARCTIC MARINE ENVIRONMENT*
}

\author{
Technical Experts/Authors \\ Melvyn G. Cowgill and Paul D. Moskowitz, Brookhaven National Laboratory \\ Lev M. Chernaenko, Interbranch Coordination Scientific-Technical Center \\ Of Nuclide Production \\ Ashot Nazarian, Science Applications International Corporation
}

\section{Project Officers}

Andrew Griffith, U.S. Department of Energy

Alexander Diashev, Russian Ministry of Defence

Thor Engøy, Norwegian Defence Research Establishment

Spring 2000

\author{
Arctic Military Environmental Cooperation \\ US Department of Defense \\ Washington, DC, USA
}

\footnotetext{
* This work was performed under the auspices of the U.S. Department of Energy under Contract No. DEAC0298CH10886.
} 


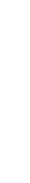

. 


\begin{abstract}
This first project, under the auspices of the Arctic Military Environmental Cooperation (AMEC) forum, Project 1.4-1 Solid Radioactive Waste Storage Technologies, successfully demonstrated the feasibility of using a polymer-based coating to seal concrete and steel surfaces from permanent radioactive contamination in an Arctic marine environment.

A mobile, self-sufficient spraying device, was developed to specifications provided by the Russian Ministry of Defence Northern Navy and was deployed at the RTP Atomflot site, Murmansk, Russia. Demonstration coatings of Polibrid 705 were applied to concrete surfaces exposed to conditions ranging from indoor pedestrian usage to heavy vehicle passage and container handling in a loading bay. A large steel container was also coated with the polymer, filled with solid radwaste, sealed, and left out of doors and exposed to the full 12 month Arctic weather cycle. The field tests were accompanied by a series of laboratory qualification tests carried out at the research laboratory of ICC Nuclide in St. Petersburg.

During the 12-month field tests, the sealant coating showed little sign of degradation except for a few chips and gouge marks on the loading bay surface that were readily repaired. Contamination resulting from radwaste handling was easily removed and the surface was not degraded by contact with the decontamination agents. In the laboratory testing, Polibrid 705 met all the Russian qualification requirements with the exception of flammability. In this last instance, it was decided to restrict application of the coating to land-based facilities.

The Russian technical experts from the Ministry of Defence quickly familiarized themselves with the equipment and were able to identify several areas of potential improvement as deployment of the equipment progressed. The prime among these was the desirability of extending the range of the equipment through enlarged gasoline tanks (to permit extended operational times) and longer material supply hoses (to increase flexibility of operation in confined spaces). Modifications designed to address these issues will be implemented as appropriate.
\end{abstract}


. 


\section{ACKNOWLEDGEMENTS}

This work was supported by the US Department of Energy, Office of Integration and Disposition and the US Department of Defense, Deputy Undersecretary for Environmental Security. The Project Officers and Technical Experts thank the Arctic Military Environmental Cooperation Principals and Steering Group for their support of these efforts. We extend a special thanks to Mr. Charles Spriggs and Promatec for their active and enthusiastic support of this program and to the directorate/staff of the RTP Atomflot site for the hosting of this demonstration. 



\section{CONTENTS}

Page

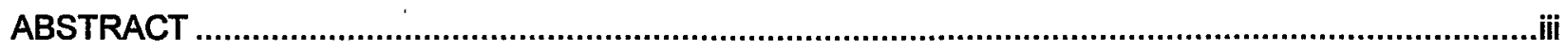

ACKNOWLEDGEMENTS ................................................................................................................ iv

FIGURES AND TABLES .............................................................................................................. vi

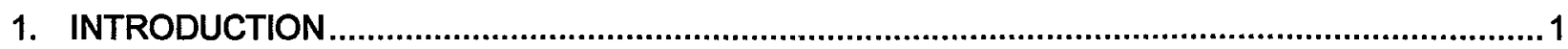

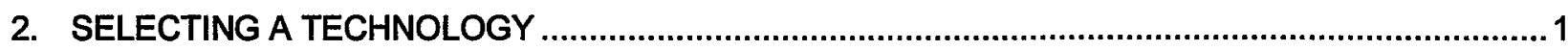

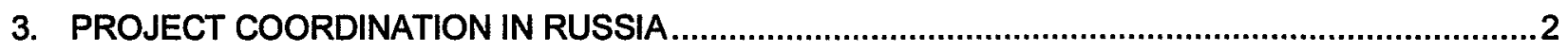

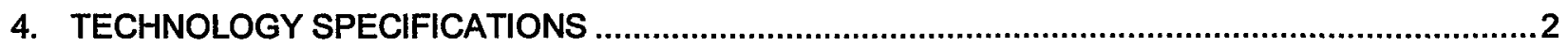

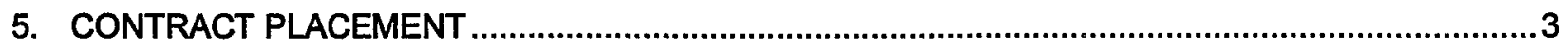

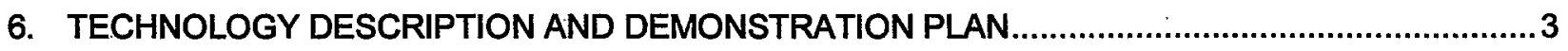

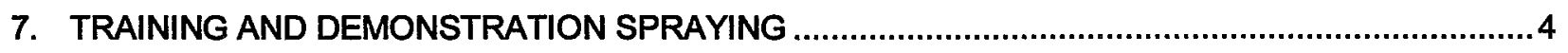

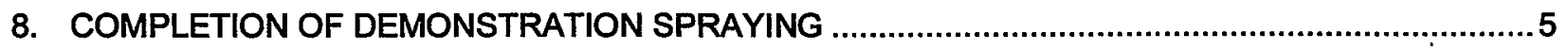

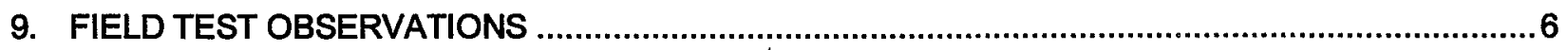

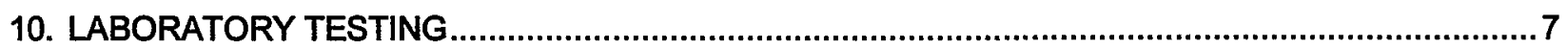

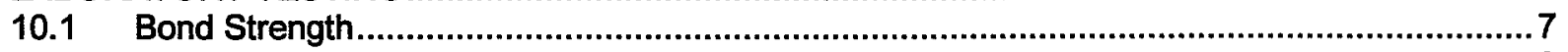

10.2 Decontamination Capability .........................................................................................

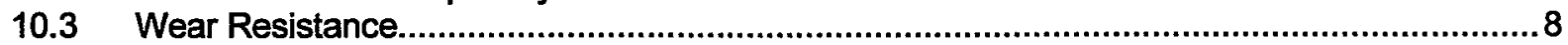

10.4 Thermal Cycling (Cold Weather) Resistance ..................................................................

10.5 Isolation Characteristics .................................................................................................

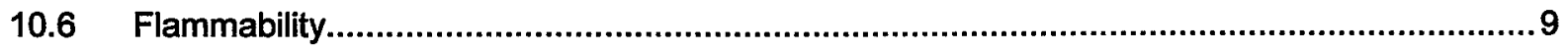

11. CONCERNS, LESSONS LEARNED, AND RECOMMENDATIONS.............................................. 


\section{FIGURES}

Page

1. Dr. Thor Engoy (NOR MOD), Andrew Griffith (U.S. DOE), RADM. Nikolai Birillo (RF MOD),

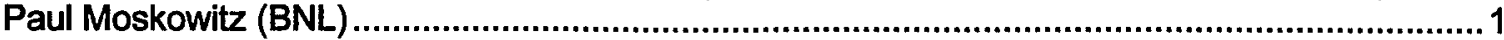

2. Map of Northwest Russia, showing locations of Northern Fleet bases...................................2

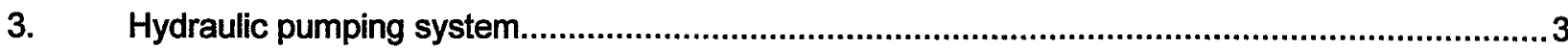

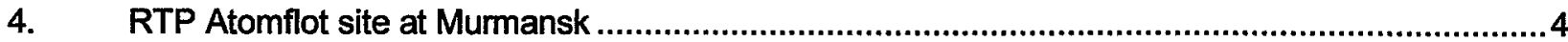

5. Polymer spray equipment inside the high bay facility at the Atomflot site in Murmansk...............4

6. Boris Chervyakov (ICC Nuclide), Alexander Treboussier (RTP Atomflot) and Charles Spriggs (Promatec) work on a clogged mixer manifold .....................................................................5

7. Mel Cowgill (BNL) and Boris Chervyakov (ICC Nuclide) examine Polibrid-coated old paint

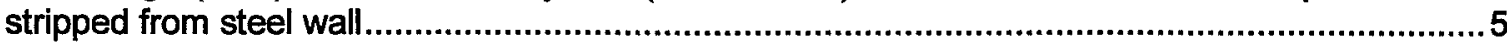

8. Russian technical expert spraying concrete floor in high-bay ...........................................6

9. Andre Abramov (RTP Atomflot) manipulating the spray equipment in a confined space ..............6

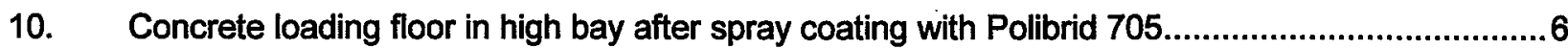

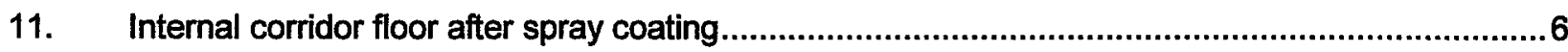

12. Polibrid coated solid radwaste container ...........................................................................

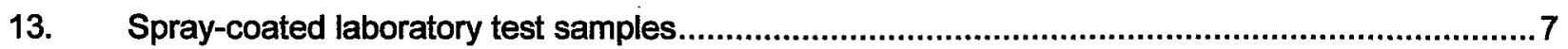

\section{TABLES}

Page

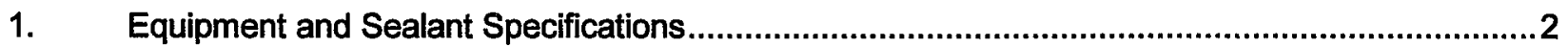

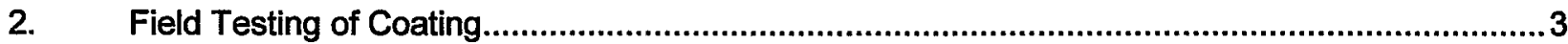

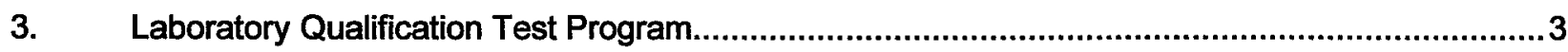

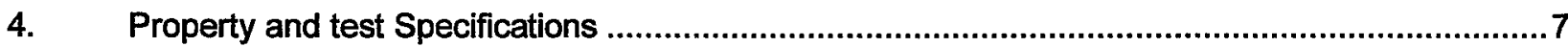

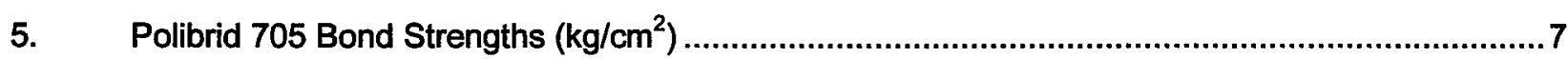

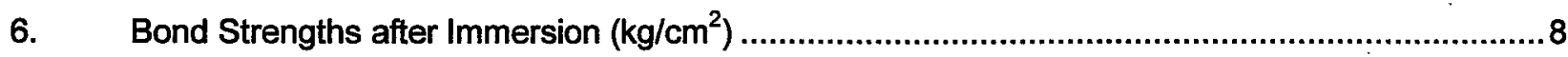

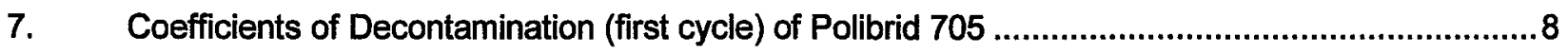

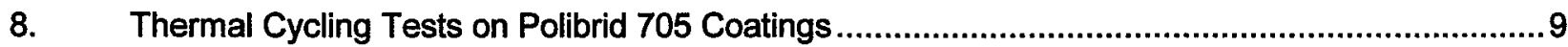




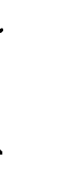




\section{INTRODUCTION}

On September 26, 1996, in Bergen, Norway, U.S. Secretary of Defense (DOD) William J. Perry, Nonwegian Minister of Defence (NOR MOD) Jorgen Kosmo, and Russian Federation Minister of Defense (RF MOD) Igor Rodionov launched a cooperative effort called the Arctic Military Environmental Cooperation (AMEC) forum. The aim of AMEC is to support dialogue and joint activities in the Arctic region among U.S., Russian, and Norwegian military and environmental officials. There are now seven project areas approved under AMEC. Five project areas deal with radioactive waste technologies:

- Naval Spent Nuclear Fuel Management (Project 1.1),

- Naval Liquid Radioactive Waste Treatment (Project 1.2),

- Technology for Solid Radioactive Waste Reduction (Project 1.3),

- Solid Radioactive Waste Storage Technologies (Project 1.4),

- Radiation Monitoring and Personnel and Environmental Safety (Project 1.5).

Two additional project areas deal with non-radioactive waste problems:

- Technologies for remediation of hazardous waste on military bases in the Arctic (Project 2.1 involves only Norway and Russia);

- "Clean ship" technologies for the collection and processing of ship-generated waste (Project 2.2).

This report presents the results of AMEC Project 1.4-1 "Performance of a Polymer Sealant Coating in an Arctic Marine Environment." This is the first of several programs under Project Area 1.4 designed to demonstrate innovative technologies that can help the RF MOD fulfill the long-term goal of safely storing radioactive wastes generated by the Russian nuclear submarine dismantlement program.

\section{SELECTING A TECHNOLOGY}

Beginning in early 1997, the AMEC participants held a series of meetings in the U.S., Norway and Russia to discuss what technologies were available that could meet specific needs identified by the RF MOD Northern Navy representatives. The key technical decisions were made at the June 1997 meetings in the U.S., hosted jointly by the U.S. Department of Energy (DOE), Brookhaven National Laboratory (BNL), and the Oak Ridge National Laboratory (ORNL). The U.S. delegation was led by Mr. Andrew Griffith, DOE; Vice-Admiral Nikolai Birillo headed the RF MOD Navy delegation; and, Dr. Thor Engøy from the Norwegian Defence Research Establishment represented the NOR MOD. At these meetings, information on a variety of relevant technologies was exchanged and U.S. vendors presented specific, practical technologies for consideration and application at the RF Northern Navy. The technologies included volume reduction systems, radioactive waste storage containers, and methods of sealing concrete and metal surfaces. The RF Navy delegation expressed

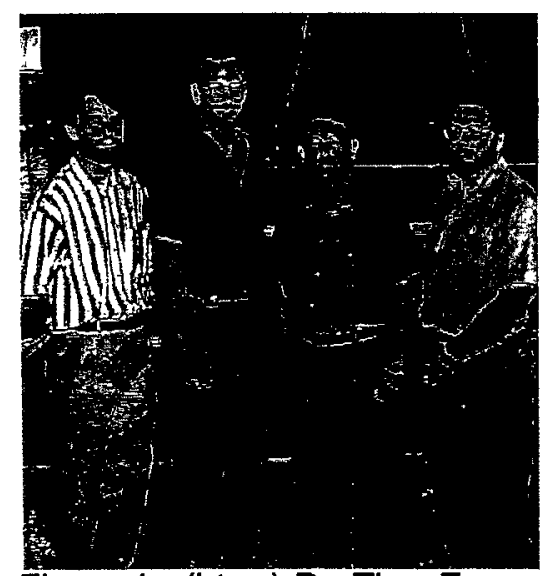

Figure 1. (I to r) Dr. Thor Engøy (NOR MOD), Andrew Griffith (U.S. DOE), VADM Nikolai Birillo (RF MOD), Paul Moskowitz (BNL). 
special interest in the sealants because of their concern for preventing permanent contamination of these structural materials during waste handling, processing and storage of radioactive wastes. Such contamination poses several problems, such as increases in worker exposures, and processing and disposal cost at end-of-life. The most promising solution appeared to lie in the use of a polymer-based sealant, so the decision was made to focus on demonstrating the viability of such a coating when deposited on concrete and metals surfaces exposed to the environmental and working conditions found at the RF Northern Navy bases.

\section{PROJECT COORDINATION IN RUSSIA}

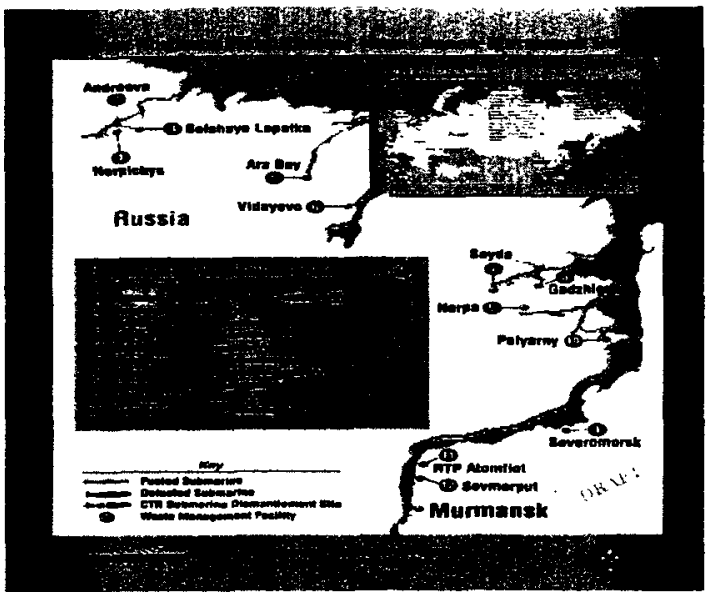

Figure 2. Map of Northwest Russia, showing locations of Northern Fleet bases.

Next to be addressed were the logistical problems associated with implementing the project, in particular the sensitivity of the RF Navy to allow U.S. DOD and NOR MOD personnel onto their bases to set up the equipment and train the Russian technicians. To this end, the RF Navy appointed the Interbranch Coordination Scientific-Technical Center of Nuclide Production (ICC Nuclide), as their agent for the program. ICC Nuclide's tasks included facilitating importation of the equipment and materials through the Russian Customs agency, and finding a suitable location for the demonstration. The latter was solved by making arrangements with the Murmansk Shipping Company to have the equipment and material delivered to the RTP Atomflot site, and to perform the training there. The site, located on the Kola River, is the headquarters of the Russian civilian nuclear icebreaker fleet and the environmental conditions there are very similar to those experienced at Andreeva Bay (Zapadnaya Litsa), the RF Northern Fleet's central radioactive waste storage facility, and the other RF Northern Navy bases. The conditions also dictated that the coating should be applied during the relatively mild weather of the summer in that region (high temperatures usually in the range $10-15^{\circ} \mathrm{C}$ ).

\section{TECHNOLOGY SPECIFICATIONS}

The next step in the project was to prepare a set of technical specifications and identify a suitable supplier for the equipment and sealant material. The specifications drafted by the RF Navy personnel, under the direction of the RF MOD Project Officer, COL Alexander Diashev, included a requirement that the equipment be mobile and self-sufficient. This was most important because it was likely that it would be used in places where utilities such as electricity and compressed air were not readily available. With regard to the sealant, enough material was to be supplied to cover an area of at least $1500 \mathrm{~m}^{2}$ to a thickness deemed sufficient to meet the needs of the application (2 to $3 \mathrm{~mm}$, depending on the substrate). The selected vendor was also to

Table 1. Equipment and Sealant Specifications

Equipment

- Stand-alone unit

- Mobile

- Own power supplies

$\bullet$

Sealant

- Resistant to marine environment

- Resistant to Arctic temperatures

- Resistant to acids, bases, organic solvents

- Resistant to permanent contamination

- Easily decontaminated

- Flammability resistance provide equipment manuals in Russian and to train RF personnel in the use of the equipment. 


\section{CONTRACT PLACEMENT}

The specifications were transmitted to Paul Moskowitz, BNL and the lead U.S. Technical Expert for Project 1.4-1, and a request-for-quote was released to potential U.S. vendors in October 1997. The final contract was placed with Promatec Technologies, Cypress, TX, in January 1998, with the shipping date set for April 30, 1998. Promatec was selected, in part, because they had already gained RF experience while working on contracts with the Russian civilian nuclear power industry. This included work with sealants at the Kola nuclear power plant.

\section{TECHNOLOGY DESCRIPTION AND DEMONSTRATION PLAN}

The Promatec technology uses an airless spray system to deposit coatings of a polymer named Polibrid 705 . The process involves preheating two components, a resin and a catalyst (called Compounds $A$ and $B$ ), using a hydraulic system to pump them to a mixer manifold, then spraying the resultant mixture onto the object surface. Polibrid 705 coatings have the advantage that they cure (harden) very rapidly and can be put into use within a very short time of being applied. This quick-setting ability of Polibrid 705 also means that, at the conclusion of each spraying operation, the mixer manifold and the spray gun must be flushed with a solvent (methyl ethyl ketone, MEK). If this is not done within a few minutes of ceasing to spray, the residual polymer will solidify in place and block this part of the delivery system. The conventional Promatec spray unit normally relies on external sources for utilities. However, in order to meet the RF Navy specifications, two gasoline engines were added, one for an electrical generator and the other for the hydraulic pump.

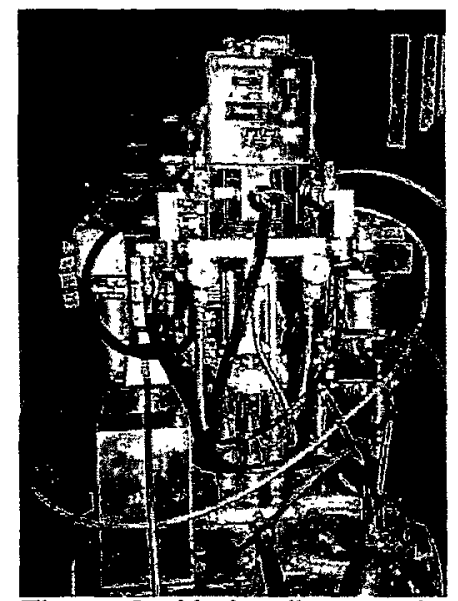

Figure 3. Hydraulic pumping system.

The Promatec technology has been proven to be effective in sealing concrete and metal structures in several non-nuclear applications. However, the polymer had not been subjected to environmental conditions as severe as those experienced at the Russian Northern Navy bases. Consequently, the RF Navy personnel met with ICC Nuclide technical staff to develop a plan to qualify the coating for use in the Arctic marine environment. This plan comprised both testing under actual field conditions (at the Atomflot site in Murmansk) and an extensive laboratory qualification test program (to be conducted at ICC Nuclide's research facility in St. Petersburg). The coatings were to be applied to concrete and to steel substrates.

\section{Table 2. Field Testing of Coating}

- Concrete surface (heavy duty)

- Concrete surfaces (light duty)

- Surfaces of metal radioactive waste containers
Table 3. Laboratory Qualification Test Program

- Coating adhesion strength

- Wear resistance

- Moisture resistance

- Resistance to low temperatures, thermal fatigue

- Flammability resistance

- Isolation properties

- Resistance to decontamination solutions

- Ease of decontaminability 


\section{TRAINING AND DEMONSTRATION SPRAYING}

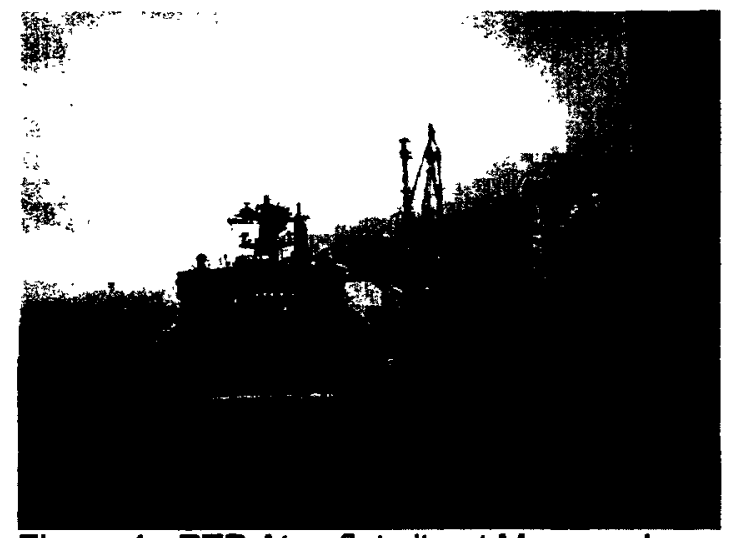

Figure 4. RTP Atomflot site at Murmansk.

The equipment and materials arrived in Murmansk at the end of May and was set up at the RTP Atomflot site adjacent to the loading dock area in a building used for storing and handling solid low-level radioactive waste. General training was then given to technical experts from the three Russian entities involved the Russian Navy, ICC Nuclide, and RTP Atomflot.

The first session began with the presentation of a video film (in Russian), in order to demonstrate how the system worked and to show examples of actual applications. Copies of a Russian translation of the equipment operating and maintenance manual were then distributed and a question-and-answer session followed, during which the U.S. party provided clarification concerning some of the properties of the polymer coating. One recurrent question was the possibility of using the polymer to seal old paint. This is not a recommended practice but, as the trainees appeared unwilling to accept this recommendation at face value, it was decided to include spray coating of old painted surfaces in the demonstration to follow.

The second session was devoted to hands-on experience with the equipment itself. It was then that several problems came to light, the most important of which was the inability to establish flow in the catalyst and the solvent feed lines. Initial attempts to correct these problems were only partially successful so the training session was temporarily suspended while phone calls and faxes were exchanged with the equipment design team in the U.S.

The delay and the subsequent work to correct the problems turned out to have a beneficial side effect in that it gave the Russian technical experts experience in disassembling and reassembling various parts of the pumping system. Promatec's experience working in Russia also proved invaluable: realizing that hand tools were often in short supply, their representative had brought along some tools of his own, which he then left with the equipment.
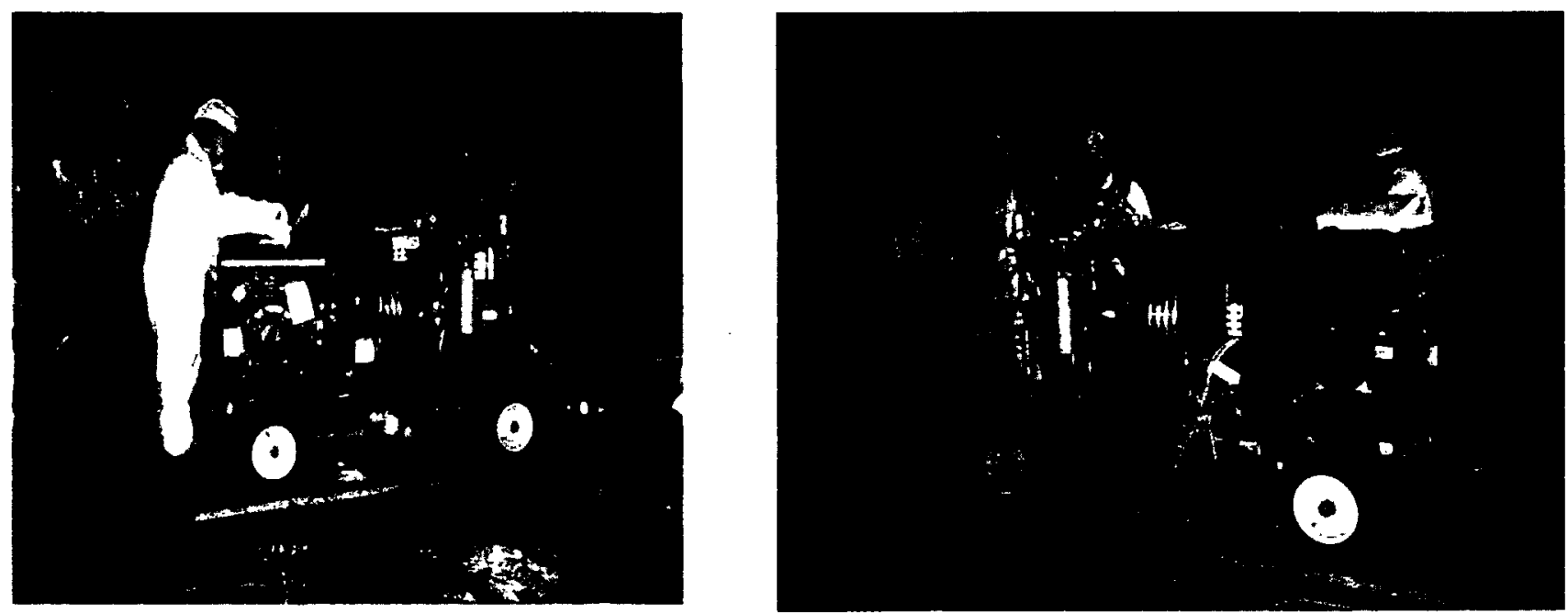

Figure 5. Polymer spray equipment inside the high bay facility at the Atomflot site in Murmansk. 
The pumping system problems were resolved, and demonstration spraying then began with a section of concrete floor and an old painted metal panel. However, another problem soon arose. It had earlier been

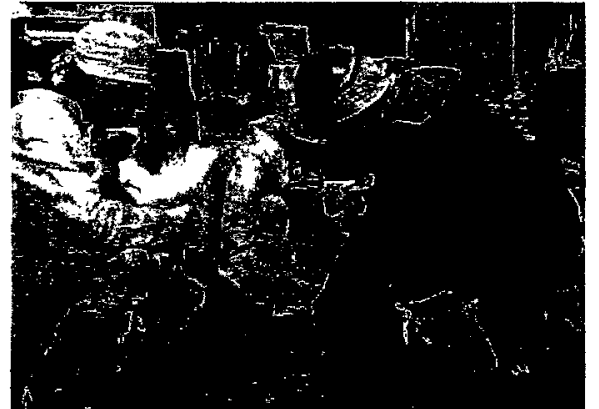

Figure 6. (I to $r$ ) Boris Chervyakov (ICC Nuclide), Alexander Treboussier (RTP Atomflot) and Charles Spriggs (Promatec) work on a clogged mixer manifold. discovered that the recommended solvent, MEK, was not available so it had been agreed, reluctantly, to try using acetone. Unfortunately, the acetone solvent proved ineffective in purging the polymer from the mixer manifold and spray gun. This meant that, between spraying sessions, the mixer manifold and spray gun had to be disassembled and cleaned manually. Again, this provided the Russian technical experts with useful experience at the time but would be a very inefficient way of operating in actual practice. It was concluded that the demonstration spraying should be discontinued until a supply of the recommended solvent, MEK, became available.

Meanwhile, the areas that had been sprayed were inspected. The coating was strongly adhesive both to the concrete and the paint. However, the paint itself could be easily stripped from the metal substrate, demonstrating that the practice of spraying over old paint was ineffective.

\section{COMPLETION OF DEMONSTRATION SPRAYING}

MEK was not available anywhere in the Russian Federation so it had to be purchased in the Netherlands, and then shipped to

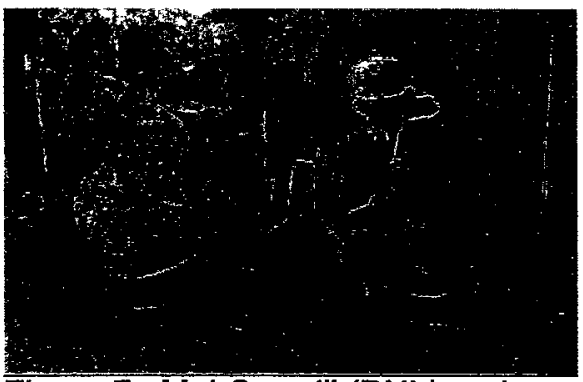

Figure 7. Mel Cowgill (BNL) and Boris Chervyakov (ICC Nuclide) examine Polibrid-coated old paint stripped from steel wall.

Russia. For this reason, further training at this time was stopped and the US team returned to the US. The U.S. team returned to Murmansk in August 1998 after the MEK was purchased and available at the Atomflot site. At this time, the training and demonstration were completed without further hindrance. The Russians personnel quickly proved their competence in operating the equipment and doing the spraying, so, after some guidance and supervision during the initial tasks, were left to work on their own.

Their immediate task was to complete spraying the $50 \mathrm{~m}^{2}$ concrete area just inside the main entrance to the high-bay area used for handling and storing solid low-level radioactive waste. They then moved to the next task which involved spraying a $1 \mathrm{~m}^{3}$ steel container and its steel plate lid. This container was to be filled with solid radioactive waste, the lid put in place, and the unit positioned on the roof of the building, exposed to the elements for one year. The session was completed with the spray coating of some concrete and metal coupons to be used in laboratory testing in St. Petersburg.

The equipment was then moved from the high bay area and Polibrid 705 applied to the floor of an internal corridor (total surface area about $250 \mathrm{~m}^{2}$ ) that would see frequent pedestrian passage. Other surfaces, including room floors in a new liquid radioactive waste facility $\left(50 \mathrm{~m}^{2}\right)$ and an internal staircase $\left(50 \mathrm{~m}^{2}\right)$, were coated later, after the U.S. party had left Murmansk. Before the fall set in, the equipment and remaining materials were placed in storage for eventual transfer from the Atomflot facility to the Russian Navy base at Andreeva Bay. 


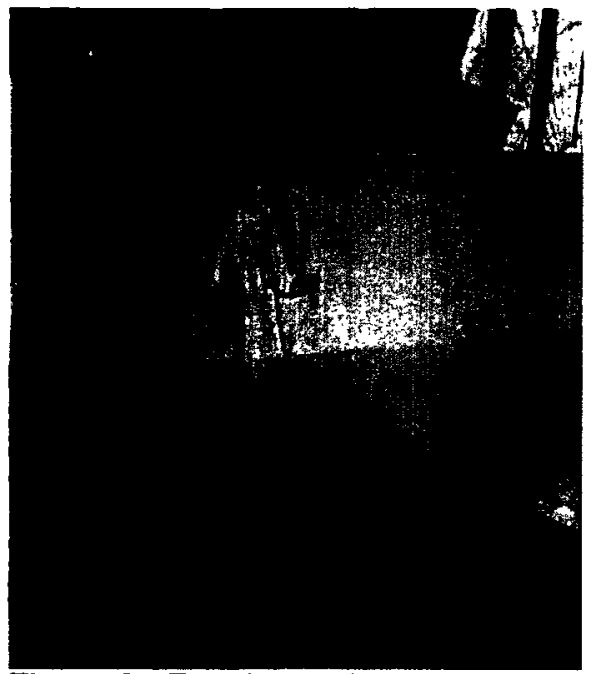

Figure 8. Russian technical expert spraying concrete floor in high-bay.

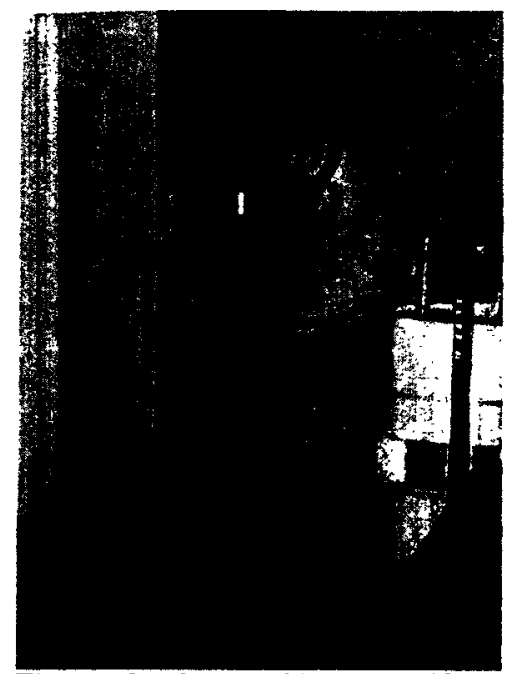

Figure 9. Andre Abramov (RTP Atomflot) manipulating the spray equipment in a confined space.

\section{FIELD TEST OBSERVATIONS}

The loading bay floor is exposed to vehicular use on a daily basis and represents possibly the most severe environment to which the coating is likely to be subjected in normal circumstances. Over the next 12 months, the temperature in the loading bay varied from $+15^{\circ} \mathrm{C}$ to $-15^{\circ} \mathrm{C}$ and the coating was subject to mechanical wear (from constant vehicle usage and handling operations), radioactive contamination, and treatment with decontamination solvents. It was also exposed to gamma radiation at an estimated

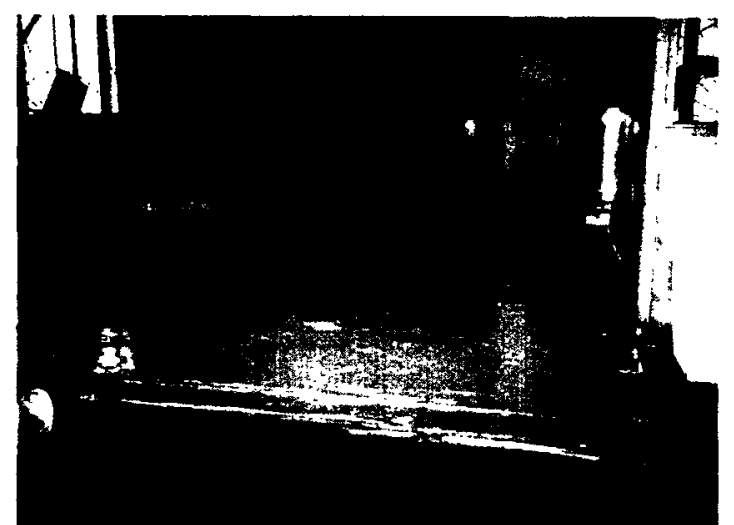

Figure 10. Concrete loading floor in high bay after spray coating with Polibrid 705.

$300 \mu R / h$ and $\beta$ contamination to a maximum level of 1000 $\mathrm{dpm} / \mathrm{cm}^{2}$. Rubber-tired vehicles caused negligible wear but damage was sustained from the use of sleds with metal runners and from the impact of metal objects during crane lifting operations. Some contamination occurred but this was removed in a single decontamination cycle. The decontamination process itself had no effect on the properties of the coating.

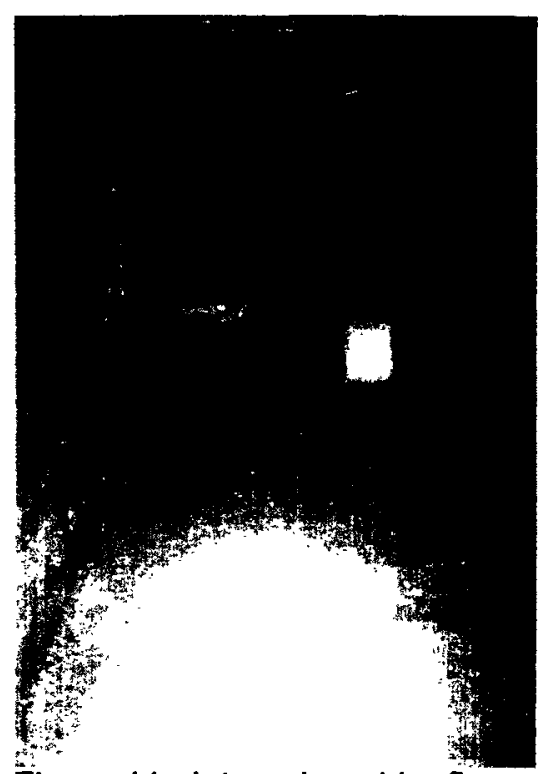

Figure 11. Internal corridor floor after spray coating. 
The conditions experienced by the coatings on the internal corridor and stairway, were less severe, with temperatures always above $0^{\circ} \mathrm{C}$. Some damage was caused by the constant passage of personnel using industrial-type footwear.

The coating on the container was exposed to temperatures as low as $-45^{\circ} \mathrm{C}$, daily temperature cycling, atmospheric precipitation (rain and snow), solar radiation, and gamma radiation (from the contained waste, estimated at about $120 \mathrm{mR} / \mathrm{h}$ ). However, it was not subjected to the kind of mechanical abuse suffered by the other coating surfaces and its durability was judged to be high.

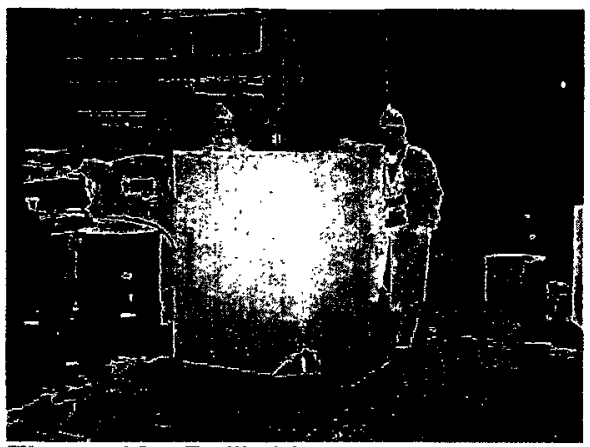

Figure 12. Polibrid coated solid radwaste container.

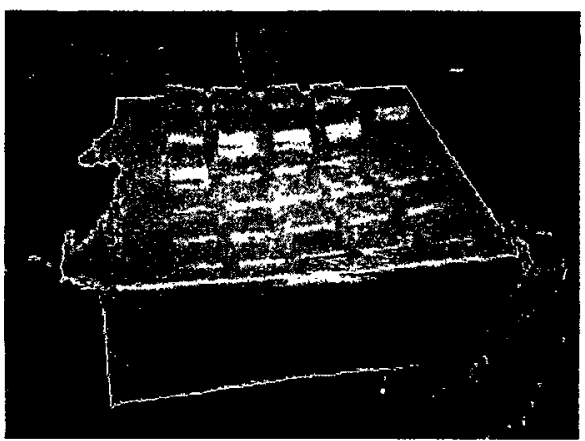

Figure 13. Spray-coated laboratory test samples.

\section{LABORATORY TESTING}

Laboratory testing was carried out at ICC Nuclide's research center in St. Petersburg. The program involved samples of both concrete $(100 \mathrm{~mm} \times 100 \mathrm{~mm}$ $\times 20 \mathrm{~mm}$ ) and steel $(100 \mathrm{~mm} \times 100 \mathrm{~mm} \times 2 \mathrm{~mm})$, some of which had been spray-coated at RTP Atomflot and the remainder brush-coated at ICC Nuclide. With the exception of the determination of bond strengths and isolation characteristics, the tests were conducted in accordance with applicable Russian Navy specifications, Bond strength tests followed a procedure proposed by BNL while ICC Nuclide developed a specific procedure to determine the isolation properties of Polibrid 705.

Table 4. Property and Test Specifications

Property

Bond strength

Decontaminability

Wear resistance

Thermal cycling

Isolation

Flammability
Test Specification

BNL procedure

GOST 27708-88

RD 95.10366-89

GOST 20811-75

GOST 6128-81

ICC Nuclide test

GOST 21227-75

ICC Nuclide test

\subsection{Bond Strength}

The experimental data indicated that Polibrid 705 coatings bonded better to steel than to concrete. However, this is a deceptive observation because, in the case of the concrete, failure always occurred in the concrete itself rather than at the concrete/coating interface. This can be attributed to the low quality of the concrete. Thus the true concrete/coating adhesion strength was unknown although it would be higher than that recorded in the current tests. The results also confirmed the importance of surface condition prior to coating application, dry clean surfaces being most desirable for good adhesion.

\section{Table 5. Polibrid 705 Bond Strengths $\left(\mathrm{kg} / \mathrm{cm}^{2}\right)$}

To steel:

- Dry surface ................... 32-36

- Corrosion on surface ........... 25

- Acid-etched surface ............ 24

- Applied on old paint .......... 31

To concrete:

- Dry surface .................. 11-15

- Wet surface ................... $<0.5$

- Applied on old paint ........... 12 
Immersion in sea water and three types of decontamination solution (SF-3K, ZPS-1M, Redox) usually caused a reduction in the bond strength of steel samples but a similar effect was not so obvious with the concrete samples, again presumably because of the problems associated with using a low quality concrete. Generally, the immersion resistance was considered to meet the Russian Navy requirements, provided that the coating was applied to a clean dry surface.

\subsection{Decontamination Capability}

Decontamination tests involved five radionuclides and three decontamination solutions. The Russian Navy requires (in OTT 6.1.40-90 and OTT 6.1.38-90) that materials used in sites with a contamination potential must be easily decontaminated. By this, it is meant that the materials must be able to stand up to 3 cycles of decontamination and that the decontamination coefficient should be approximately 10 in the first cycle.

In the tests conducted by ICC Nuclide, these criteria were met by both materials for all radionuclides using the ZPS-1M solution and for all except Cs-137 using the SF-3K preparation. However, when the Polibrid 705 was decontaminated with a redox solution, decontamination coefficients were low (2 to 4.5$)$ in all cases and the surface became visibly porous.

Table 7. Coefficients of Decontamination (first cycie) of Polibrid 705

\begin{tabular}{|c|c|c|c|c|}
\hline \multirow[b]{2}{*}{ Radionuclide } & \multicolumn{2}{|c|}{ Bonded to Steal } & \multicolumn{2}{|c|}{ Bonded to Concrete } \\
\hline & SF-3K & ZPS-1M & SF-3K & ZPS-3M \\
\hline Cs-137 & 5.2 & 21 & 3.5 & 10 \\
\hline Co-60 & 33 & 30 & 9.3 & 9.3 \\
\hline Eu-152 & 163 & - & 162 & - \\
\hline Sr-90 & 165 & - & 80 & - \\
\hline Pu-239 & 84 & - & 400 & - \\
\hline
\end{tabular}

Considering that the predominant contaminating radionuclide is usually Co-60, the test results indicated that the decontamination capability of Polibrid 705 is satisfactory when either SF-3K or ZPS-1M are used. However, if Cs-137 is the predominant contaminant, then only the ZPS-1M solution should be used.

\subsection{Wear Resistance}

The wear resistance tests involved making 2000 abrasive strokes using a special device, followed by visual examination of the coating surface. The Polibrid 705 coatings showed no damage and the mass loss was only $0.0021 \mathrm{~g}$. Thus the coatings were judged to meet the requirements of the Russian Navy.

\subsection{Thermal Cycling (Cold Weather) Resistance}

Three tests were performed at ICC Nuclide's laboratory in St. Petersburg while a fourth test was done at the National Institute of Standards and Technology (NIST) in the U.S.A.

Two of the St. Petersburg tests involved a similar thermal cycle sequence: 6 hours at $-40^{\circ} \mathrm{C}$ followed by 8 hours at $20^{\circ} \mathrm{C}$, repeated 5 times. The first of these tests was performed on the initial ingredients 
(Compounds $A$ and $B$ ). After the sequence the two compounds were mixed to determine if any coagulation had taken place. In the second test, the thermal cycles were applied to coatings of Polibrid 705 on concrete and steel, after which the coatings were examined visually then adhesion tests performed. The results of the two tests indicated that neither the initial ingredients nor the coating had degraded.

The third test at St. Petersburg involved the application of 25 cycles between $-20^{\circ} \mathrm{C}$ and $+20^{\circ} \mathrm{C}$ to coatings on both concrete and steel, after which adhesion strengths were measured. In this case, bond strengths decreased significantly from those of the as-deposited coatings. However, it was concluded that the coatings still met the Russian Navy requirements.

The NIST test, based on ASTM D1211, used coatings on concrete and steel, and a free film, and involved a thermal cycle of one hour at $-21^{\circ} \mathrm{C}$ followed by at least one hour at $+25^{\circ} \mathrm{C}$. Specimen surfaces were examined with a special optical-digital microscope daily until the prescribed number of cycles had been accumulated $(50,100,150,200)$. No visible $(<0.1 \mu \mathrm{m})$ cracks were observed, leading to the conclusion that the coating could be successfully applied in a climate with frequent sharp temperature drops.

\begin{tabular}{|c|c|c|c|c|}
\hline Location & Temps. $\left({ }^{\circ} \mathrm{C}\right)$ & Cycles & Test & Results \\
\hline Nuclide & -20 to +20 & 5 & $\begin{array}{l}\text { Visual } \\
\text { Adhesion }\end{array}$ & $\begin{array}{l}\text { No change } \\
\text { No change }\end{array}$ \\
\hline NIST & -21 to +25 & $\begin{array}{c}25 \\
200\end{array}$ & $\begin{array}{l}\text { Adhesion } \\
\text { Visual }\end{array}$ & $\begin{array}{l}\text { Reduced strength } \\
\text { No cracking }\end{array}$ \\
\hline
\end{tabular}

\subsection{Isolation Characteristics}

The isolation tests were performed to determine the feasibility of using Polibrid 705 to isolate fixed radioactive contamination on containers and other surfaces. To this end, samples of steel and concrete were contaminated with appropriate radionuclides then coated with Polibrid 705 . Smears were subsequently taken at specified intervals after the application of the coating and estimates made of the proportions of radionuclide that had diffused through the coating. The results from the first three months of testing indicated the highest proportions were only $10^{-3}$ (for Cs-137 and Co-60) and thus Polibrid 705 had good isolating characteristics.

\subsection{Flammability}

The two tests used by ICC Nuclide to assess flammability are unlike any of the standard methods used in the U.S. (e.g., NFPA 255 and ASTM D 3806). The GOST 21227-75 required coating a piece of aluminum foil, holding it over a naked flame for 10 seconds, and observing how much is burnt. In the case of Polibrid 705, the coating burned completely and it thus failed to meet the Navy requirement for the charred area not to exceed $60 \mathrm{~mm}$. The second (and non-standard) test performed at ICC Nuclide used a gasoline-induced fire around a $100 \mathrm{~mm}$ cubic container coated with $2 \mathrm{~mm}$ of Polibrid 705 . In this case, the coating was burnt almost completely burnt through on two sides. The results of these two tests raised some concern among the Navy personnel about the flammability resistance and threatened to be a "show stopper." The Russian tests were examined in depth and compared with the results of a flame spread test (ASTM D 3806) performed in the U.S. on an aluminum sheet $(10 \mathrm{~cm} \times 60 \mathrm{~cm})$ with a $1 \mathrm{~mm}$ thick Polibrid coating. These latter results had indicated that Polibrid 705 self-extinguished after the flame source had been removed. After much discussion, it was decided to limit the application. of Polibrid coatings to shore-based facilities. 


\section{CONCERNS, LESSONS LEARNED, AND RECOMMENDATIONS}

As the Russian technical experts continued to use the equipment, they were able to identify some operational concerns and recommend methods by which these concerns could be rectified. None of the concerns presented a major stumbling block to the general deployment of the technology but attention to them could result in greater efficiencies.

Limited Operation Time. The capacity of the gas tank for the hydraulic pump unit was such that only one hour of continuous spraying could be accomplished before refueling was necessary. It was recommended that the capacity be increased so that it would be possible to work a whole shift (4-5 hours) without having to take a refueling break. Related to this, the personnel also felt their efficiency would be improved by lengthening the hoses that delivered the material from the equipment to the spray head. The present system is adequate when coating large open areas but work in more confined spaces (corridors, staircases, adjacent small rooms) required frequent shut down of the spraying equipment while it was maneuvered into a different location.

Short Curing Time. The short curing time (5-7 minutes) meant that the spray head had to be flushed immediately after each spraying session, no matter how short, otherwise the Polibrid 705 would solidify in it. Increasing the curing time would permit relocation of the equipment short distances without the timeconsuming need to flush the spray head then restart the operation.

MEK Usage. Related to the short curing time, the Russian technical experts expressed concern that once-through usage of MEK was very costly. They recommended that using a formulation with a longer curing time would help reduce solvent usage. However, Promatec has recommended a recycling procedure that is used by the U.S. industry. This procedure helps to minimize disposal costs because the recycling continues until the volume of MEK is practically exhausted (due to natural vaporization).

Quality Control. The Russian technical experts identified some factors that affected quality control of the coatings.

- During operation, some parts of the equipment (hoses and pressure gauges) became gummed up with coating material. When the coating quality was controlled by pressure gauge readings, as recommended in the manual, uneven coatings, as indicated by variations in color, were obtained. Later, bubbles appeared on the surfaces, the coating became fragile, and flaking occurred. The Russian operatives found that, in practice, they produced higher quality coatings if they relied on the visual judgment of the coating color.

- Unstable spraying occurred when the levels of the coating ingredients (Compounds A and B) in the drums fell below about $25 \%$. This resulted in an excess of either resin or catalyst in the mixture and a low-quality coating. The Russian operators also noted the usage rate of catalyst to be somewhat higher than that stated in the manual.

Repair Work. Repair work on damaged areas was labor-intensive. In particular, the repair of a small area using the spray equipment led to material wastage because of the short time of the actual application. The alternative, performing the repair with a brush application, did not produce a good quality result.

Promatec is now reviewing the above observations, and equipment and material modifications will be implemented as appropriate. 